\title{
ORAL CLONIDINE DECREASES BLEEDING IN ENDOSCOPIC SINUS SURGERY
}

Hassanali Soltani MD, Jalal Hashemi MD, Mostafa Hashemi MD, Mitra Jabalameli MD

Department of Anesthesia and Critical Care, Alzahra Hospital, Isfahan University of Medical Sciences, Isfahan, Iran, 8174673461

INTRODUCTION: Serious complications usually result from impaired visibility due to excessive bleeding during endoscopic sinus surgery (ESS) [1]. The aim of this study was to assess the effect of premedication of clonidine as a central alpha agonist and an antihypertensive drug in producing a bloodless surgical field in ESS and also to evaluate bleeding volume.

METHODS: After approval of the institutional ethics committee and obtain informed consent this clinical trial was performed on 113 adult patients scheduled for elective ESS under general anesthesia. Fifty-two patients received clonidine (5 mic.g/ kg) 90 min prior to arrival at the operating theater (clonidine group) and sixty-one received placebo (control group). The hemodynamic endpoint of the anesthetic management was to maintain the mean arterial pressure at $70 \mathrm{mmHg}$ in order to produce a bloodless surgical field. The desired control of the cardiovascular system was obtained using halothane (inspired concentration increments of $0.5 \mathrm{vol} \%$ up to 1.5 vol\%), fentanyl (2mic.g/ kg, iv up to $4 \mathrm{mic} . \mathrm{g} / \mathrm{kg}$ ) and hydralazine (100 mic.g / $\mathrm{kg}$ iv up to $40 \mathrm{mg}$ ) as needed. Intraoperative bleeding was assessed on a six - point scale from $0=$ no bleeding to $5=$ severe bleeding. In addition to above scoring, aspirated bleeding volume was also measured via a scaled bottle at the end of operation. Data were analyzed using chi-square, fisher's exact and student t-test.

RESULTS: There was less bleeding volume in the clonidine group than in the placebo group (144 \pm 75 vs. $225 \pm 72 \mathrm{ml}, \mathrm{P}<0.05)$. Frequency of score 3 and 4 of bleeding (troublesome with repeated suction) was lower in the clonidine group (12\% vs. $35 \%$, $\mathrm{P}<0.05)$. Fentanyl requirement was significantly lower in clonidine group (112 $\pm 18 \mathrm{vs.}$ $142 \pm 21$ mic.g, $\mathrm{P}<0.05)$.

DISCUSSION: In the previous two studies, premedication with oral clonidine significantly had been reduced bleeding in middle ear microsurgery [2,3]. In present study premedication with oral clonidine reduced bleeding in ESS and also diminished fentanyl and hydralazine requirement for controlled hypotension.

\section{REFERENCES:}

1) Otolaryngol Head Neck Surg. 122(4):560-566

2) Acta Anesth Scand. 45(5):627-633

3) Ann Fr Anesth Reanim. 11(2):125-131 